\title{
Influence of hospitalization on potentially inappropriate prescribing among elderly patients in a Malaysian community
}

\author{
Muhammad Eid Akkawi, Mohamad Haniki Nik Mohamed \\ Kulliyyah of Pharmacy, International Islamic University Malaysia, Kuantan, Malaysia \\ *For correspondence: Email: mhdeidak@gmail.com; Tel: 0060-186675232
}

Sent for review: 25 September 2017

Revised accepted: 7 October 2017

\begin{abstract}
Purpose: To compare the prevalence and type of potentially inappropriate medications (PIMs) and potential prescribing omissions (PPOs) on admission and discharge of patients, and to determine the associated predictors.

Methods: This was a prospective observational study conducted in the multidisciplinary medical and surgical units of Hospital Tengku Ampuan Afzan (HTAA), Malaysia. The medications of patients who had been admitted to the hospital from community-dwelling settings were reviewed to identify PIMs/PPOs using version 2 of STOPP/START criteria. A logistic regression model was applied to detect the risk factors associated with PIM or PPO at discharge.

Results: Among the 300 patients involved in the study, the prevalence of PIMs was $27 \%$ upon admission, which decreased to $22.3 \%$ at discharge $(p=0.014)$ with PIMs pertaining to increasing the risk of physical falls in elderly people being the most common for pre- and post-hospitalization. The prevalence of PPOs was $47.6 \%$ upon admission, which increased to $48 \%$ at discharge $(p=0.99)$, with the omission of musculoskeletal medications being the most common PPOs at admission and discharge. Having a PIM at discharge was associated with the number of discharge medications and the history of falls, whereas having a high comorbidity index score or history of falls was associated with having a PPO at discharge.

Conclusion: Hospitalization significantly reduces the prevalence of PIMs, but not PPOs or polypharmacy, among elderly patients. The number of discharge medications and the history of falls are predictors of discharge PIM, whilst high comorbidities and the history of falls were the predictors of discharge PPO. Improving the knowledge of hospital practitioners regarding geriatric pharmacotherapy is required to optimize prescribing in elderly patients during hospitalization.
\end{abstract}

Keywords: Hospitalization, STOPP criteria, START criteria, Inappropriate prescribing, Co-morbidity, Polypharmacy, Elderly patients

\begin{abstract}
This is an Open Access article that uses a funding model which does not charge readers or their institutions for access and distributed under the terms of the Creative Commons Attribution License (http://creativecommons.org/licenses/by/4.0) and the Budapest Open Access Initiative (http://www.budapestopenaccessinitiative.org/read), which permit unrestricted use, distribution, and reproduction in any medium, provided the original work is properly credited.

Tropical Journal of Pharmaceutical Research is indexed by Science Citation Index (SciSearch), Scopus, International Pharmaceutical Abstract, Chemical Abstracts, Embase, Index Copernicus, EBSCO, African Index Medicus, JournalSeek, Journal Citation Reports/Science Edition, Directory of Open Access Journals (DOAJ), African Journal Online, Bioline International, Open-J-Gate and Pharmacy Abstracts
\end{abstract}

\section{INTRODUCTION}

Potentially inappropriate prescribing (PIP) occurs when there is prescribing of a potentially inappropriate medication (PIM), where the risks associated with the medication outweigh the expected benefits, or when there is a potential prescribing omission (PPO), where a specific 
medication is indicated but not yet prescribed $[1,2]$. Several studies have demonstrated the association between PIP and adverse drug reactions (ADRs) [3], increase in hospitalizations $[4,5]$, decrease in patients' adherence [6], and excess costs [7,8]. PIP is highly common in older adults[9]; and because of physiological and pathological changes occurring with advancing age, the negative outcomes of PIPs in elderly patients are of great concern [1].

Inappropriate prescribing can be detected by either explicit or implicit criteria. Implicit criteria are judgment-based tools, whereas explicit criteria are criterion-based ones. Explicit criteria are developed from literature reviews and expert opinions, and are then endorsed using consensus techniques. Several explicit criteria have been formulated to identify PIPs in elderly patients. Among the most widely-used tools are the screening tool of older persons' prescriptions (STOPP), and the screening tool to alert doctors to right treatment (START). The STOPP/START criteria were first introduced in 2008 [10], and were then updated and validated in 2014.[11]. The STOPP list comprises 80 criteria for identifying PIMs that should be avoided, either in all elderly adults or when there is drug-disease or drug-drug interaction. The START list contains 34 criteria that address the common PPOs.

Studies comparing different explicit criteria have concluded that the STOPP criteria are more sensitive than other available explicit criteria in detecting PIMs that are associated with ADRs $[3,12,13]$. Additionally, a systematic review of randomized controlled trials deduced that the use of the STOPP criteria reduces falls, duration of hospitalization, and treatment costs [2]. The use of the STOPP/START criteria has been expanding since their first release [2], and the criteria showed a good inter-rater reliability with physicians and pharmacists [14,15]. The European Union Geriatric Medicine Society (EUGMS) has announced its support for the STOPP/START criteria [16].

The prevalence of PIP among elderly patients varies significantly, depending on the study design, tools used, and the targeted population. A multi-centre study conducted on hospitalized elderly patients in six European countries found a prevalence ranging from 34.7 to $77.3 \%$ for PIMs, and from 51.3 to $72.7 \%$ for PPOs, according to the STOPP/START criteria [17]. A comparable prevalence rate of 51 and $74 \%$ for PIMs and PPOs, respectively was reported by an Australian hospital [18].
Hospital admissions seem to offer a chance for healthcare professionals (HCPs) to comprehensively review the medications of patients, optimize the prescribing and, therefore, reduce pre-admission PIMs and PPOs. However, minimizing PIPs in acute care settings is challenging. This may be due to lack of time, multiple interventions in the same patients by different specialists with difficulty of full coordination, and limited number of medications in hospital formularies[9]. Studies that compared the prevalence rate of PIPs pre- and posthospitalization found that the results were incompatible. These studies reported a decrease $[19,20]$, increase [21], or insignificant change $[22,23]$ in PIMs after hospitalization. As far as is known, there is no published study available that has assessed the impact of hospitalization on PIPs among elderly patients in Malaysia. Hence, this study was designed and conducted for the situation in the Malaysia as due to differences in the healthcare systems, available medications, and prescribing patterns between countries, it cannot be assumed that the prevalence and types of PIPs in all countries are identical.

The main objectives of this study were: to assess the impact of hospitalization on PIPs in community-dwelling elderly patients by comparing the prevalence and type of PIMs and PPOs pre- and post-hospitalization as identified by version 2 of the STOPP/START criteria; and to identify the factors associated with having a PIM or PPO upon discharge.

\section{METHODS}

\section{Study design and setting}

This study was a prospective observational study that took place in the multidisciplinary medical and surgical units of Hospital Tengku Ampuan Afzan (HTAA), Kuantan, Pahang, Malaysia from April to October 2016. HTAA is a tertiary hospital, with a capacity for 794 beds. Each involved unit consisted of 4 wards; 2 for men and 2 for women, with a total of 326 beds in the two units. The study was conducted in accordance with the guidelines of Declaration of Helsinki [24]. Ethical approval was obtained from Medical Research and Ethics Committee, Ministry of Health Malaysia (no. NMRR-15-718-25235), and from the Clinical Research Center (CRC) of the hospital. Informed consent was obtained from all the patients involved in the study.

\section{Study population}

Five hundred and seventeen consecutive community-dwelling inpatients were screened for 


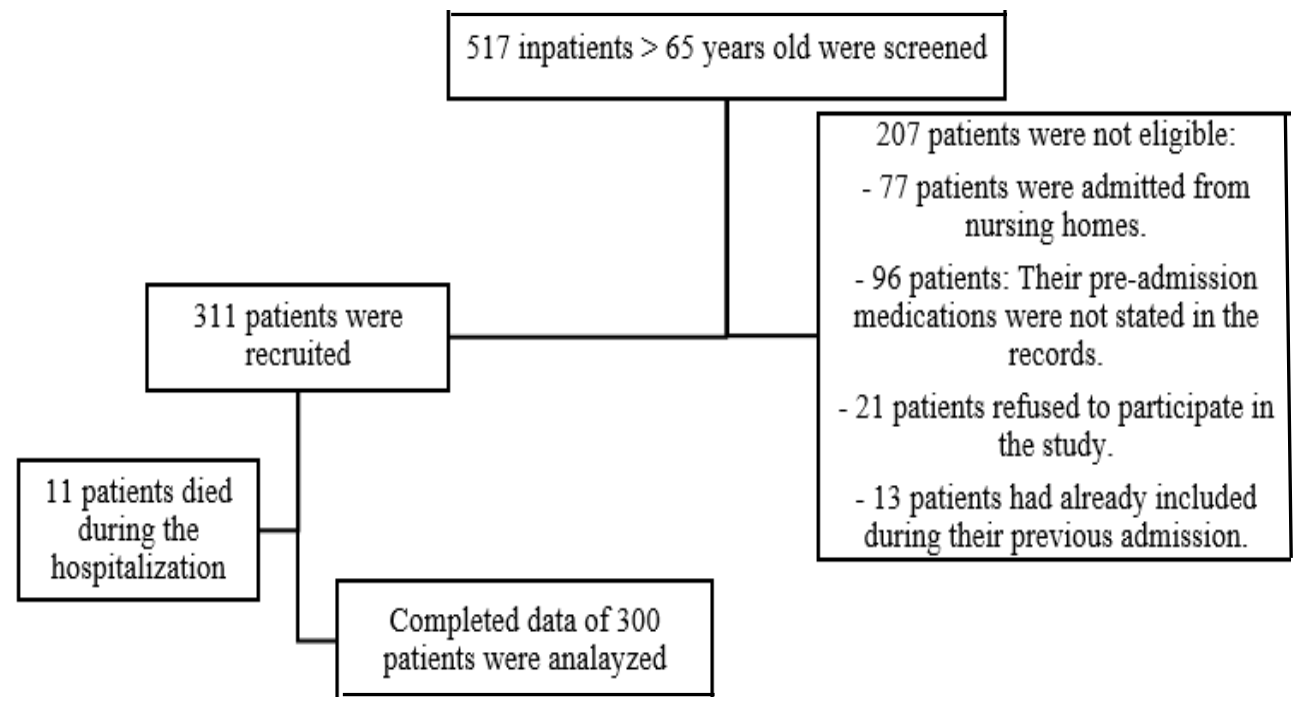

Figure 1: Flowchart of the patient recruitment process

eligibility (Figure 1). Patients above 65 years who were admitted to the hospital for any medical or surgical reason, and who were on at least one medication for a minimum of three months prior to their hospitalization, were screened. Patients were excluded if they were living in long-term care facilities, e.g. nursing homes, could not speak or were unable to communicate in English or Malay, or if their pre-admission medications were not clearly stated in their records. Patients who died during hospitalization were also excluded. Patients who had multiple admissions during the study period were included during their first admission only. Eligible patients were identified daily from the admission records of each ward.

\section{Data collection}

Two trained pharmacists extracted the information from the patients' records. This was followed by face-to-face interviews. The patients were approached individually and were given a verbal explanation about the study together with an information sheet written in Malay or English. The patients were monitored until their discharge. However, the pharmacists did not interfere with the treatment of the patients.

The data extraction form included the demographic details of the patients, their date of admission and discharge, vital signs, serum creatinine, abnormal laboratory results, chief complaint, final diagnosis, comorbidities, preadmission medications, discharge medications, history of hospitalizations, past medical history. The details of their past medications were retrieved from the patients' record and by directly asking them, or their caregivers, if further related information was required. All patient's medications were considered in the study; including prescribed, over the counter, topical and inhaled medications. The comorbidities were scored using the age-combined Charlson Comorbidity Index (CCl) [25]. The patients' activities of daily living (ADL) were assessed by the Katz scale [26] to identify disabled patients. The score of Katz scale ranges from 0 (totally independent patient) to 6 (highly dependent patient). The creatinine clearance was calculated using the Cockcroft Gault formula [27] for nonobese patients and the Salazar Corcoran formula [28] for obese patients (patients with body mass index $\geq 30$ ).

\section{Potentially inappropriate prescribing and polypharmacy}

The pre-admission and discharge medications of the patients were reviewed twice by the pharmacist in the study to identify the PIMs and PPOs using version 2 of the STOPP/START criteria. Polypharmacy is defined as taking five or more medications concurrently [29].

\section{Statistical analysis}

The data were analysed using the Statistical Package for the Social Sciences version 24.0 (IBM SPSS Statistics 24). The prevalence of PIMs (or PPOs) was defined as the percentile portion of patients who had at least one PIM (or PPO). Shapiro-Wilk normality test was performed to test the normality of continuous variables, and to subsequently select the statistical tests. McNemar's test was used to assess the effect of hospitalization on the prevalence of PIMs and PPOs at pre- and posthospitalization. Wilcoxon signed-rank test was used to detect differences between the number 
of medications, PIMs, and PPOs on admission and discharge. A multivariate logistic regression was employed to predict the risk factors for having PIM or PPO at the time of discharge. The variables included in the logistic regression model were age, sex, history of falls during the past three months, history of hospitalization during the last year, duration of hospitalization, age-combined $\mathrm{CCl}$, number of discharge medications, and ADL status, which was treated as a dichotomous variable (either independent in all Katz scale aspects or dependent in at least one aspect). The significance level was set at 5 $\%$.

\section{RESULTS}

\section{Characteristics of the study population}

Of the 300 participants, 133 (44\%) were females. The mean \pm SD age was $72 \pm 6$ years. The sample involved the three main ethnic groups in Malaysia, namely, Malays, Chinese, and Indians. Table 1 gives the details about the characteristics of the study population. One hundred and twenty-eight (42.6\%) patients had an age-combined $\mathrm{CCl}$ score of 5 or more, and

Table 1: Characteristics of the study population $(\mathrm{N}=$ 300 patients)

\begin{tabular}{|c|c|c|}
\hline \multirow{2}{*}{\multicolumn{3}{|c|}{$\begin{array}{l}\text { Variable } \\
\text { Gender }\end{array}$}} \\
\hline & & \\
\hline & Female & $133(44)$ \\
\hline & Male & $167(56)$ \\
\hline \multicolumn{3}{|l|}{ Age } \\
\hline & Mean (SD) years & $72(6)$ \\
\hline & Median (Range, IQR) years & $\begin{array}{c}70(65-93 \\
67-75)\end{array}$ \\
\hline \multicolumn{3}{|l|}{ Race } \\
\hline & Malay & $218(72.7)$ \\
\hline & Chinese & $63(21)$ \\
\hline & Indian & $19(6.3)$ \\
\hline \multicolumn{3}{|c|}{ Length of hospital stay } \\
\hline & Mean $(S D)$ days & $5.4(3.7)$ \\
\hline & Median (Range, IQR) days & $4(1-21,3-7)$ \\
\hline \multicolumn{3}{|c|}{ Frequent comorbidity } \\
\hline & Hypertension & $261(87)$ \\
\hline & Diabetic mellitus & $179(59.7)$ \\
\hline & Hyperlipidemia & $78(26)$ \\
\hline & Chronic kidney disease & $73(24.3)$ \\
\hline & Ischemic heart disease & $61(20.3)$ \\
\hline Depend & ent in $\geq 1 \mathrm{ADL}$ & $107(35.6)$ \\
\hline \multicolumn{3}{|c|}{ Age-combined CCl } \\
\hline & $1-3$ & $90(30)$ \\
\hline & $4-7$ & $196(65.3)$ \\
\hline & $8-10$ & $14(4.7)$ \\
\hline \multicolumn{2}{|c|}{$\begin{array}{l}\text { Experienced falls in the past three } \\
\text { months }\end{array}$} & $52(17.3)$ \\
\hline \multicolumn{2}{|c|}{ Hospitalized in the last year } & $183(61)$ \\
\hline & t where otherwise in & $\begin{array}{l}\text { activities of } \\
\text { index; SD }\end{array}$ \\
\hline
\end{tabular}

107 were dependent in at least one ADL. The most encountered comorbidities were hypertension, followed by diabetes mellitus.

\section{Prescribed medications and polyphar- macy}

Table 2 shows the number of prescribed medications and PIPs on admission and discharge. Patients were prescribed a mean \pm SD of $5.5 \pm 2.4$ and $5.7 \pm 2.5$ medications on admission and discharge, respectively; which showed no significant difference $(p=0.99$; Wilcoxon signed-ranks test). Polypharmacy was seen in 198 (66 \%) and 199 (66.3\%) patients at pre- and post-hospitalization, respectively ( $p=$ 0.99; McNemar's test). The number of medications decreased in 75 patients, while it increased in 105 patients.

\section{Potentially inappropriate medications (PIMs) at pre- and post-hospitalization}

On admission, $27 \%$ (81 patients; 97 PIMs) of the patients were on at least one PIM. Of these patients, 4 patients were on 3 PIMs (Table 2). Eighteen $(22.5 \%)$ out of the 80 STOPP criteria were represented on admission and/or discharge.

The three most common PIMs on admission and discharge were vasodilators, that increase the risk of falls, and that were used on patients with persistent postural hypotension (31 and 28 patients pre- and post-hospitalization, respecttively); metformin, that was used on patients with $\mathrm{ClCr}<30 \mathrm{~mL} / \mathrm{min}$ (13; 10 patients); and $\beta$ blockers, that were used on patients with frequent hypoglycemic episodes (10; 10 patients) (Table 3).

On discharge, the prevalence of PIMs was reduced to $22.3 \%$ (67 patients; 85 PIMs; $p=$ 0.014; McNemar's test). All the PIMs were stopped in 21 patients; however, 7 patients were introduced to new PIMs, while they were not on any PIM on admission (Table 4).

There was no significant difference in the number of PIMs per patient before and after hospitalization ( $p=0.06$; Wilcoxon signed-ranks test). Moreover, none of the individual STOPP criteria significantly changed after discharge, meaning that there was no change in the pattern of PIM prescribing pre- and post-hospitalization (McNemar's test) (Table 3). The applied logistic regression model to test the predictors of having PIM at discharge was statistically significant, where $x^{2}=15.59, p=0.04$. It revealed that the absolute number of medications at discharge 
Table 2: Number of medications and PIPs at pre-and post-hospitalization

\begin{tabular}{lccc}
\hline & $\begin{array}{c}\text { Admission } \\
\mathbf{N}(\%)^{*}\end{array}$ & $\begin{array}{c}\text { Discharge N } \\
(\%)^{*}\end{array}$ & $\begin{array}{c}\text { Significance } \\
(\boldsymbol{p} \text { value })\end{array}$ \\
\hline Medication & 1660 & 1273 & \\
Total & $5.5(2.4)$ & $5.7(2.5)$ & \\
Mean (SD) & $(1-11,4-7)$ & $6(1-14,4-7)$ & 0.99 \\
Median (Rang, IQR) & $102(34)$ & $101(33.7)$ & 0.99 \\
1-4 medications & $182(60.7)$ & $175(58.3)$ & 0.68 \\
5-9 medications & $16(5.3)$ & $24(8)$ & 0.57 \\
$\geq 10$ medications & & & \\
PIMs & $219(73)$ & $233(77.7)$ & 0.014 \\
No PIM & $68(22.7)$ & $53(17.7)$ & 0.038 \\
1 PIM & $13(4.3)$ & $14(4.6)$ & 0.99 \\
$\geq 2$ PIMs & & & \\
PPOs & $157(52.4)$ & $156(52)$ & 0.99 \\
No PPO & $96(32)$ & $101(33.6)$ & 0.522 \\
1 PPO & $34(11.3)$ & $31(10.4)$ & 0.69 \\
2 PPOs & $13(4.3)$ & $12(4)$ & 0.99 \\
$\geq 3$ PPOs &
\end{tabular}

${ }^{\star}$ Except where otherwise indicated; SD standard deviation; IQR interquartile range

Table 3: Potentially Inappropriate Medications PIMs identified by the STOPP criteria, N=300

\begin{tabular}{|c|c|c|}
\hline Type of PIMs according to the STOPP criteria & $\begin{array}{l}\text { Admission } \\
\mathbf{N}(\%)\end{array}$ & $\begin{array}{l}\text { Discharge } \\
\text { N (\%) }\end{array}$ \\
\hline \multicolumn{3}{|l|}{ Drug Indication Criteria } \\
\hline "Any duplicate drug class prescription" & $5(1.7)$ & $3(1)$ \\
\hline \multicolumn{3}{|l|}{ Cardiovascular System } \\
\hline "Beta-blocker in combination with verapamil or diltiazem" & 0 & $1(0.3)$ \\
\hline \multicolumn{3}{|l|}{ Antiplatelet/Anticoagulant Drugs } \\
\hline $\begin{array}{l}\text { "Aspirin plus clopidogrel as secondary stroke prevention, unless the patient has } \\
\text { a coronary stent(s) inserted in the previous } 12 \text { months or concurrent acute } \\
\text { coronary syndrome or has a high grade symptomatic carotid arterial stenosis" }\end{array}$ & $5(1.7)$ & $3(1)$ \\
\hline $\begin{array}{l}\text { "Aspirin in combination with vitamin } \mathrm{K} \text { antagonist, direct thrombin inhibitor or } \\
\text { factor Xa inhibitors in patients with chronic atrial fibrillation" }\end{array}$ & $1(0.3)$ & 0 \\
\hline Ticlopidine in any circumstances & $7(2.3)$ & $7(2.3)$ \\
\hline \multicolumn{3}{|l|}{ Central Nervous System and Psychotropic Drugs } \\
\hline "Benzodiazepines for $\geq 4$ weeks" & $1(0.3)$ & 0 \\
\hline "First-generation antihistamines" & $1(0.3)$ & $1(0.3)$ \\
\hline \multicolumn{3}{|l|}{ Renal System } \\
\hline "NSAID's if eGFR $<50 \mathrm{ml} / \mathrm{min} / 1.73 \mathrm{~m}^{<"}$ & $1(0.3)$ & 0 \\
\hline "Metformin if eGFR $<30 \mathrm{ml} / \mathrm{min} / 1.73 \mathrm{~m}^{2} "$ & $13(4.3)$ & $10(3.3)$ \\
\hline \multicolumn{3}{|l|}{ Gastrointestinal System } \\
\hline $\begin{array}{l}\text { "Drugs likely to cause constipation in patients with chronic constipation where } \\
\text { non-constipating alternatives are available" }\end{array}$ & $1(0.3)$ & $1(0.3)$ \\
\hline \multicolumn{3}{|l|}{ Respiratory System } \\
\hline $\begin{array}{l}\text { "Systemic corticosteroids instead of inhaled corticosteroids for maintenance } \\
\text { therapy in moderate-severe COPD" }\end{array}$ & $1(0.3)$ & 0 \\
\hline $\begin{array}{l}\text { "Anti-muscarinic bronchodilators with a history of narrow angle glaucoma or } \\
\text { bladder outflow" }\end{array}$ & $3(1)$ & $2(0.7)$ \\
\hline \multicolumn{3}{|l|}{ Musculoskeletal System } \\
\hline "NSAID with severe hypertension" & $1(0.3)$ & 0 \\
\hline $\begin{array}{l}\text { "Long-term NSAID or colchicine ( }>3 \text { months) for chronic treatment of gout where } \\
\text { there is no contraindication to a xanthine-oxidase inhibitor" }\end{array}$ & $3(1)$ & $2(0.7)$ \\
\hline \multicolumn{3}{|l|}{ Endocrine System } \\
\hline "Sulphonylureas with a long duration of action with type 2 diabetes mellitus" & $2(0.7)$ & $1(0.3)$ \\
\hline "Beta-blockers in diabetes mellitus with frequent hypoglycemic episodes" & $10(3.3)$ & $10(3.3)$ \\
\hline \multicolumn{3}{|l|}{ Drugs that predictably increase the risk of falls in older people } \\
\hline $\begin{array}{l}\text { "Vasodilator drugs with persistent postural hypotension" } \\
\text { Analgesic Drugs }\end{array}$ & $31^{*}(10.3)$ & $28^{* *}(9.3)$ \\
\hline "Use of regular opioids without concomitant laxative" & 0 & $3(1)$ \\
\hline
\end{tabular}


Table 4: Changes in PIM at pre- and post-hospitalization

\begin{tabular}{cccccc}
\hline $\begin{array}{c}\text { Having at least } \\
\text { one PIM on } \\
\text { admission }\end{array}$ & $\begin{array}{c}\text { Discharged } \\
\text { with no PIM }\end{array}$ & $\begin{array}{c}\text { Discharged } \\
\text { with reduced } \\
\text { number of } \\
\text { PIMs }\end{array}$ & $\begin{array}{c}\text { Discharged } \\
\text { with increased } \\
\text { number of } \\
\text { PIMs }\end{array}$ & $\begin{array}{c}\text { Discharged with } \\
\text { no change in } \\
\text { number of PIMs }\end{array}$ & $\begin{array}{c}\text { Patients with } \\
\text { newly introduced } \\
\text { PIMs at } \\
\text { discharge }\end{array}$ \\
\hline $81(27 \%)$ & $21(7.67 \%)$ & $3(1 \%)$ & $6(4.2 \%)$ & $50(16.67 \%)$ & $7(2.3 \%)$ \\
\hline PIM potentially inappropriate medication & & &
\end{tabular}

Table 5: Potentially prescribing omissions (PPOs) identified by START criteria $(\mathrm{N}=300)$

\begin{tabular}{|c|c|c|}
\hline Type of PPOs according to START criteria & $\begin{array}{l}\text { Admission } \\
\text { N (\%) }\end{array}$ & $\begin{array}{l}\text { Discharge } \\
\quad \mathrm{N}(\%)\end{array}$ \\
\hline \multicolumn{3}{|l|}{ Cardiovascular system } \\
\hline $\begin{array}{l}\text { "Antiplatelet therapy with a documented history of coronary, cerebral or } \\
\text { peripheral vascular disease" }\end{array}$ & $13(4.3)$ & $11(3.7)$ \\
\hline $\begin{array}{l}\text { "Statin therapy with a documented history of coronary, cerebral or } \\
\text { peripheral vascular disease" }\end{array}$ & $10(3.3)$ & $12(4)$ \\
\hline $\begin{array}{l}\text { "Angiotensin Converting Enzyme (ACE) inhibitor with systolic heart failure } \\
\text { and/or documented coronary artery disease" }\end{array}$ & $33(11)$ & $33(11)$ \\
\hline "Beta-blocker with ischemic heart disease" & $25(8.3)$ & $24(8)$ \\
\hline $\begin{array}{l}\text { "Appropriate beta-blocker (bisoprolol, nebivolol, metoprolol or carvedilol) } \\
\text { with stable systolic heart failure" }\end{array}$ & $5(1.7)$ & $6(2)$ \\
\hline \multicolumn{3}{|l|}{ Respiratory system } \\
\hline $\begin{array}{l}\text { "Regular inhaled B2 agonist or antimuscarinic bronchodilator mild to } \\
\text { moderate asthma or COPD" }\end{array}$ & $18(6)$ & $16(5.3)$ \\
\hline "Regular inhaled corticosteroid for moderate-severe asthma or COPD" & $16(5.3)$ & $11(3.7)$ \\
\hline \multicolumn{3}{|l|}{ Musculoskeletal system } \\
\hline $\begin{array}{l}\text { "Vitamin D supplement in older people who are housebound or } \\
\text { experiencing falls or with osteopenia" }\end{array}$ & $40(13.3)$ & $40(13.3)$ \\
\hline "Xanthine-oxidase inhibitors with a history of recurrent episodes of gout" & $3(1)$ & $2(0.6)$ \\
\hline \multicolumn{3}{|l|}{ Endocrine system } \\
\hline $\begin{array}{l}\text { "ACE inhibitor or Angiotensin Receptor Blocker (if intolerant of ACE } \\
\text { inhibitor) in diabetes with evidence of renal disease" }\end{array}$ & $19(6.3)$ & $20(6.7)$ \\
\hline \multicolumn{3}{|l|}{ Urogenital system } \\
\hline $\begin{array}{l}\text { "Alpha-1 receptor blocker with symptomatic prostatism, where } \\
\text { prostatectomy is not considered necessary" }\end{array}$ & $10(3.3)$ & $10(3.3)$ \\
\hline $\begin{array}{l}\text { "5-alpha reductase inhibitor with symptomatic prostatism, where } \\
\text { prostatectomy is not considered necessary" }\end{array}$ & $13(4.3)$ & $13(4.3)$ \\
\hline
\end{tabular}

(OR: 1.17, $95 \% \mathrm{Cl} 1.038-1.32$ ) and a previous experience of falls (OR 2.33, $95 \% \mathrm{Cl} 1.19$ 4.56)were significantly associated with the increased possibility of having PIM at discharge. The most common encountered PIMs in patients with history of falls were using vasodilators that increase the risk of falls followed by using two medications from the same drug class (duplicate drug class prescription).

\section{Potentially prescribing omissions (ppos) at pre- and post-hospitalization}

One hundred and forty-three patients (47.6\%) admitted to the hospital were having at least one PPO, with a total of 207 PPOs. One patient presented with 5 PPOs. The prevalence increased on discharge to $48 \%$ (144 patients, 201 PPOs; $p=0.99$, McNemar's test), with also one patient discharged with 5 PPOs (different from the one on admission) (Table 2). Out of the 34 START criteria, 12 (35\%) were encountered on admission and discharge. The most commonly found PPO categories in descending order of frequency were PPOs pertaining to the cardiovascular system, musculoskeletal system, and respiratory system (Table 5). No significant changes were found either in the number of PPOs ( $p=0.5$; Wilcoxon signed-rank test) or in the individual START criteria on discharge (McNemar's test) (Table 5). Hospitalization corrected all the PPOs in 11 patients. However, new PPOs were identified on discharge in 12 patients, who did not have any PPO on admission. The applied logistic regression model to test the predictors of having PIM at discharge was statistically significant, where $x^{2}=53.36, p<$ 0.001 . It revealed that a previous experience of falls (OR 10, $95 \% \mathrm{Cl}$ 4.26-22.28), and agecombined $\mathrm{CCl}$ (OR 1.21, $95 \% \mathrm{Cl} 1.01-1.44$ ) were significantly associated with having PPOs on discharge. The most frequently reported PPOs in patients with history of falls were the omission in vitamin $D$ supplement, the omission of angiotensin-converting enzyme (ACE) inhibitor in diabetic patients with renal failure, and the 
omission of $5-\alpha$ reductase inhibitor in patients with prostatism.

\section{DISCUSSION}

This study reported the influence of hospitalization on the prevalence of polypharmacy and PIPs, as defined by the STOPP/START criteria, among hospitalized community-dwelling elderly patients. The study revealed a significant decrease in the prevalence of PIMs coupled with an insignificant increase in the prevalence of PPOs. The study also found no changes in terms of the number of prescribed medications or polypharmacy at pre- and posthospitalization.

A limited number of studies have been conducted to compare the prevalence of PIPs on admission and discharge, and their results were contradictory due to variations in terms of the study design, the detection tool used, hospital settings, and the characteristics of the study population.

Wickop et al [22] reported an insignificant change in the prevalence of PIMs using three different explicit criteria - including the STOPP criteria - in a teaching hospital in Germany. Another study from Australia by Poudel et al [23] involving patients above 70 years old, who were admitted to a hospital from community-dwelling or longterm care facilities, also showed an insignificant reduction in PIMs on discharge using Beers Criteria.

A Norwegian study by Bakken et al [30] found a significant increase in PIMs, according to the NORGEP criteria, amongst community-dwelling people aged $\geq 70$ years, who were admitted to internal medicine and orthopaedic surgery wards. In contrast, Onatade et al reported a significant reduction in PIMs in the Specialist Health and Ageing Unit in the UK using the STOPP criteria [20]. Compared with the number of studies that addressed this issue in western countries, little is known about this in the Asian region. Chen et al [31] Investigated the prevalence of PIMs at discharge amongst inpatients admitted to the medical wards of a Taiwanese hospital using STOPP criteria. The study revealed a prevalence rate of $36.2 \%$. However, the authors reported no data about the prevalence of PIMs prior to admission. Morimoto et al [32] conducted a study in three Japanese hospitals, where they found a prevalence of $56.1 \%$ of PIMs on admission according to the Beers Criteria.

This study used the latest version (version 2) of STOPP/START criteria, in which some of the old criteria had been deleted and new ones added. However, most of the available published studies used version 1 of the criteria and this may further explain the differences between the results of this study and the results found in other studies. One of the most encountered STOPP categories on admission and discharge was "using drugs that predictably increase the risk of falls in older people", which was also reported as one of the top classes of PIMs used in other studies $[3,17,20,21,31]$, yet the types of drugs may have been different. The prescribing of these kinds of drugs to elderly patients is of concern since it is associated with falls and fracture-related hospitalizations [4]. The newly-added PIMs were quite common in the study population, which may indicate the importance of the recent updating of the STOPP criteria. PIMs pertaining to renal function and antiplatelet/anticoagulant drugs were both the second highest common STOPP categories.

The use of benzodiazepines -in patients at risk of falls- was reported as a common PIM in several studies $[17,21,35,36]$, whereas it was not encountered in the present study. This may be due to the low use of benzodiazepines in older patients in Malaysia, which was also reported by other researchers from a nursing home in Malaysia [37]. Other common PIMs that were reported in several studies [3,18,20,34], according to the STOPP criteria, were "aspirin with no history of coronary, cerebral or peripheral arterial occlusive symptoms" and "long-term opioids in patients with falls". However, these criteria were removed from version 2 of the STOPP/START criteria.

The significant decrease in the prevalence of PIMs at discharge may reflect an overall tendency of practitioners in the current hospital toward correcting pre-admission medications. On the other hand, failure to change any of the individual STOPP criteria for pre- and posthospitalization could be attributed partially to a lack of knowledge on the part of HCPs about the special criteria for prescribing for elderly patients. It is worth noting here that only 14 out of the 80 STOPP criteria were found at discharge in the current study, which was fewer than that reported in other studies $[20,21]$. This shows that the inappropriate prescribing was concentrated in limited classes of medications, and the prescribing may be improved by boosting the knowledge of HCPs about these classes of medications.

In the current study, the prevalence of PPOs on admission $(47.6 \%)$ was lower than the average rate reported in six different European countries 
[17] (59.4\%), and higher than that observed in South Korea [38]. However, the prevalence of PPOs on discharge (48\%) was consistent with that of a study in Taiwan [31]. The insignificant impact of hospitalization on PPOs, as observed in this study, resembled that found by Manias et al [18], who reported a prevalence rate for PPOs of 60 and $63 \%$ on admission and discharge, respectively. On the contrary, the results of the current study differed from those obtained in a study by Frankenthal et al, where there was a significant reduction in the prevalence of PPOs from $41 \%$ on admission to $28.3 \%$ on discharge [21].

The most common PPO identified in the current study was the omission of vitamin $D$ supplements in patients with a history of falls (13\% pre- and post-hospitalization), which was newly-added to version 2 of the STOPP/START criteria. Anyway, the omission of vitamin $D$ and calcium supplements was also common in other studies, but in patients with another coexisting risk factor, namely osteoporosis [17,21]. The omission of musculoskeletal medications is similar to prescribing medications predicting falls, it is associated with fall and fracture-related hospitalizations [4].

The second most common PPO was the omission of ACE inhibitor (11\% pre- and posthospitalization) in patients with documented coronary artery diseases (CAD), which was a common PPO in previous studies $[31,39]$. The third most common PPO was the omission of Badrenergic blocker in patients with documented CAD ( 8.3 and $8 \%$ pre- and post-hospitalization), although this omission was not one of the top prevalent PPOs in other studies. Urogenital System PPOs, a new category under the START criteria, were also relatively common in the current study $(7.6 \%$ pre- and posthospitalization), where the $\alpha-1$ receptor blocker and $5-\alpha$ reductase inhibitor were omitted in patients with symptomatic prostatism. Other frequently reported START criteria in the literature $[17,21,31]$, such as the "omission of aspirin or statin for the primary prevention of cardiovascular disease in diabetes mellitus", were removed from version 2 of the START criteria.

The current study showed that each additional medication prescribed at discharge increases the probability of having PIM by 1.2 times. It is obviously foreseeable that increasing the number of medications is associated with increasing the possibility for one of them to be inappropriate, and this is confirmed by other studies $[17,20]$. A high comorbidity index (age-combined $\mathrm{CCl}$ ) score and history of falls are predictors of having PPOs at discharge. It is normal that having more diseases require more medications, where some of them may be inappropriately omitted, and this is consistent with the findings of other studies $[17,40]$. Additionally, it is not surprising that a recent experience of a fall is a predictor of having PIM and PPO, since the most prevalent PIM and PPO in the current study population were related to having a risk or history of falls.

\section{Strengths and limitations of the study}

This study had some limitations. It was conducted in one hospital only, and since there were no other similar studies in Malaysia to compare it with, it could not be assumed that the findings represent the practice in all Malaysian hospitals. Additionally, some information that was required to apply the criteria could not be retrieved, and that may have resulted in an underestimation of the prevalence of PIPs. For instance, no record was found pertaining to pneumonia or influenza vaccinations, which were required as part of the START criteria. On the other hand, we believe that this is the first study in Malaysia to have applied the STOPP/START criteria for hospitalized elderly patients and to have investigated the influence of hospitalization on PIPs.

\section{CONCLUSION}

The findings of this study indicate that hospitalization reduces the prevalence of preadmission PIMs among community-dwelling elderly patients. However, it did not influence the prevalence of PPOs or polypharmacy among this population. The most prevalent PIM at pre- and post-hospitalization is the prescribing of medications that increase the risk of falls in elderly patients and the most encountered PPO is the omission of vitamin $D$ supplements in patients with a history of falls. The newly-added criteria of version 2 of the STOPP/START criteria are not uncommon in the study population. Having a history of fall or increasing the number of medications on discharge was associated with increasing the likelihood of having PIM, whilst having a high comorbidity index score or history of falls was a predictor of having PPO at discharge. Further studies in other Malaysian acute healthcare settings are required, and investigating the impact of educational interventions on the prescribing practices of hospital HCPs is of important value in future studies.

\section{DECLARATIONS}




\section{Acknowledgement}

The authors would like to thank the heads of the medical and surgical departments at Hospital Tengku Ampuan Afzan (HTAA) for giving access to their patients and their records for the purpose of this study. This study was funded by the International Islamic University Malaysia (IIUM) Research Initiative Grant Scheme (no. RIGS 15098-0098).

\section{Conflict of interest}

No conflict of interest is associated with this work.

\section{Contribution of authors}

We declare that this work was done by the author(s) named in this article and all liabilities pertaining to claims relating to the content of this article will be borne by the authors. This study is part of MEA's PhD research. The study was designed by MEA and MHNM. The study was conducted by MEA and supervised by MHNM. MEA analysed the data and wrote the

\section{REFERENCES}

1. O'Connor MN, Gallagher P, O'Mahony D. Inappropriate Prescribing: Criteria, Detection and Prevention. Drugs Aging 2012; 29(6): 437-452.

2. Hill-Taylor B, Walsh KA, Stewart S, Hayden J, Byrne S, Sketris IS. Effectiveness of the STOPP/START (Screening Tool of Older Persons' potentially inappropriate Prescriptions/Screening Tool to Alert doctors to the Right Treatment) criteria: Systematic review and meta-analysis of randomized controlled studies. J Clin Pharm Therapeut 2016; 41(2): 158-169.

3. Hamilton $H$, Gallagher $P$, Ryan $C$, Byrne $S$, O'Mahony $D$. Potentially inappropriate medications defined by STOPP criteria and the risk of adverse drug events in older hospitalized patients. Arch Intern Med 2011; 171(11): 1013-1019.

4. Dalleur O, Spinewine A, Henrard S, Losseau C, Speybroeck $N$, Boland B. Inappropriate prescribing and related hospital admissions in frail older persons according to the STOPP and START criteria. Drugs and Aging 2012; 29(10): 829-837.

5. Van der Stelt CAK, Vermeulen Windsant-van den Tweel AMA, Egberts ACG, Van den Bemt PMLA, Leendertse AJ, Hermens WAJJ, Van Marum RJ, Derijks HJ. The Association Between Potentially Inappropriate Prescribing and Medication-Related Hospital Admissions in Older Patients: A Nested Case Control Study. Drug Saf 2016; 39(1): 79-87.

6. Mansur $N$, Weiss $A$, Beloosesky $Y$. Is there an association between inappropriate prescription drug use and adherence in discharged elderly patients? Ann Pharmacother 2009; 43(2): 177-184.

7. Cahir C, Bennett K, Teljeur C, Fahey T. Potentially inappropriate prescribing and adverse health outcomes in community dwelling older patients. $\mathrm{Br} J$ Clin Pharmacol 2014; 77(1): 201-210.

8. Morgan SG, Hunt J, Rioux J, Proulx J, Weymann D, Tannenbaum C. Frequency and cost of potentially inappropriate prescribing for older adults: a crosssectional study. CMAJ open 2016; 4(2): 346-351.

9. Page $R L$, Linnebur SA, Bryant LL, Ruscin JM. Inappropriate prescribing in the hospitalized elderly patient: Defining the problem, evaluation tools, and possible solutions. Clin Interv Aging 2010; 5(1): 75-87.

10. Gallagher P, Ryan C, Byrne S, Kennedy J, O'Mahony D. STOPP (Screening Tool of Older Person's Prescriptions) and START (Screening Tool to Alert doctors to Right Treatment). Consensus validation. Int $\mathrm{J}$ Clin Pharmacol Ther 2008; 46(2): 72-83.

11. O'Mahony D, O'Sullivan D, Byrne S, O'Connor MN, Ryan $C$, Gallagher P. STOPP/START criteria for potentially inappropriate prescribing in older people: version 2. Age Ageing 2015; 44(2): 213-218.

12. Gallagher $P$, O'Mahony D. STOPP (Screening Tool of Older Persons' potentially inappropriate Prescriptions): Application to acutely ill elderly patients and comparison with Beers' criteria. Age Ageing 2008; 37(6): 673-679.

13. Curtain CM, Bindoff IK, Westbury JL, Peterson GM. A Comparison of Prescribing Criteria When Applied to Older Community-Based Patients. Drugs Aging 2013; 30(11): 935-943.

14. Ryan C, O'Mahony D, Byrne S. Application of STOPP and START criteria: Interrater reliability among pharmacists. Ann Pharmacother 2009; 43(7-8): 12391244.

15. Gallagher $P$, Baeyens J-P, Topinkova E, Madlova $P$, Cherubini A, Gasperini B, Cruz-Jentoft A, Montero B, Lang $P O$, Michel J-P, O'Mahony $D$. Inter-rater reliability of STOPP (Screening Tool of Older Persons' Prescriptions) and START (Screening Tool to Alert doctors to Right Treatment) criteria amongst physicians in six European countries. Age Ageing 2009; 38(5): 603-609.

16. Cruz-Jentoft AJ. New therapies for an ageing Europe: 2011 EUGMS Málaga Congress. Eur Geriatr Med 2011; 2(2): 128.

17. Gallagher $P$, Lang $P O$, Cherubini A, Topinková E, CruzJentoft $A$, Montero Errasquín $B$, Mádlová $P$, Gasperini $B$, Baeyens $H$, Baeyens $J P$, et al. Prevalence of potentially inappropriate prescribing in an acutely ill population of older patients admitted to six European hospitals. Eur J Clin Pharmacol 2011; 67(11): 11751188.

18. Manias E, Kusljic S, Lam D-L. Use of the Screening Tool of Older Persons' Prescriptions (STOPP) and the Screening Tool to Alert doctors to the Right Treatment (START) in hospitalised older people. Australas $J$ Ageing 2015; 34(4): 252-258.

Trop J Pharm Res, January 2018; 17(1): 159 
19. Laroche M-L, Charmes J-P, Nouaille Y, Fourrier A, Merle L. Impact of hospitalisation in an acute medical geriatric unit on potentially inappropriate medication use. Drugs Aging 2006; 23(1): 49-59.

20. Onatade R, Auyeung V, Scutt G, Fernando J. Potentially inappropriate prescribing in patients on admission and discharge from an older peoples' unit of an acute uk hospital. Drugs and Aging 2013; 30(9): 729-737.

21. Frankenthal $D$, Lerman $Y$, Lerman $Y$. The impact of hospitalization on potentially inappropriate prescribing in an acute medical geriatric division. Int J Clin Pharm 2014; 37(1): 60-67.

22. Wickop B, Härterich S, Sommer C, Daubmann A, Baehr $M$, Langebrake $C$. Potentially Inappropriate Medication Use in Multimorbid Elderly Inpatients: Differences Between the FORTA, PRISCUS and STOPP Ratings. Drugs - Real World Outcomes 2016; 3(3): 317-325.

23. Poudel A, Peel NM, Nissen L, Mitchell C, Gray LC, Hubbard RE. Potentially inappropriate prescribing in older patients discharged from acute care hospitals to residential aged care facilities. Ann Pharmacother 2014; 48(11): 1425-1433.

24. Czarkowski M. Helsinki Declaration--next version. Pol Merkur Lekarski 2014; 36(215): 295-297.

25. Charlson M, Szatrowski TP, Peterson J, Gold J. Validation of a combined comorbidity index. J Clin Epidemiol 1994; 47(11): 1245-1251.

26. Katz S, Downs TD, Cash HR, Grotz RC. Progress in Development of the Index of ADL. Gerontol 1970; 10(1): 20-30.

27. Cockcroft DW, Gault H. Prediction of Creatinine Clearance from Serum Creatinine. Nephron 1976; 16(1): 31-41.

28. Salazar DE, Corcoran GB. Predicting creatinine clearance and renal drug clearance in obese patients from estimated fat-free body mass. Am J Med 1988; 84(6): 1053-1060.

29. Gnjidic D, Hilmer SN, Blyth FM, Naganathan V, Waite L, Seibel MJ, McLachlan AJ, Cumming RG, Handelsman $D J$, Le Couteur DG. Polypharmacy cutoff and outcomes: five or more medicines were used to identify communitydwelling older men at risk of different adverse outcomes. J Clin Epidemiol 2012; 65(9): 989-995.

30. Bakken MS, Ranhoff $A H$, Engeland $A$, Ruths $S$. Inappropriate prescribing for older people admitted to an intermediate-care nursing home unit and hospital wards. Scand J Prim Health Care 2012; 30: 169-175.

31. Liu CL, Peng LN, Chen YT, Lin MH, Liu LK, Chen LK. Potentially inappropriate prescribing (IP) for elderly medical inpatients in Taiwan: A hospital-based study. Arch Gerontol Geriatr 2012; 55(1): 148-151.

32. Sakuma M, Morimoto T, Matsui K, Seki S, Kuramoto N, Toshiro J, Murakami J, Fukui T, Saito M, Hiraide A, Bates DW. Epidemiology of potentially inappropriate medication use in elderly patients in Japanese acute care hospitals. Pharmacoepidemiol Drug Saf 2011; 20(4): 386-392.

33. National Institute for Clinical Excellence. Gastrooesophageal reflux disease and dyspepsia in adults: investigation and management. NICE guideline (cg184); 2014.

34. Wahab MSA, Nyfort-Hansen K, Kowalski SR. Inappropriate prescribing in hospitalised Australian elderly as determined by the STOPP criteria. Int J Clin Pharm 2012; 34(6): 855-862.

35. Frely A, Chazard E, Pansu A, Beuscart JB, Puisieux F. Impact of acute geriatric care in elderly patients according to the Screening Tool of Older Persons' Prescriptions/Screening Tool to Alert doctors to Right Treatment criteria in northern France. Geriatr Gerontol Int 2016; 16(2): 272-278.

36. Gutiérrez-Valencia R, Izquierdo M, Malafarina V, AlonsoRenedo J, González-Glaría B, Larrayoz-Sola B, Monforte-Gasque MP, Latasa-Zamalloa P, MartínezVelilla N. Impact of hospitalization in an acute geriatric unit on polypharmacy and potentially inappropriate prescriptions: A retrospective study. Geriatr Gerontol Int 2017: 1-7.

37. Chen $L L$, Tangiisuran $B$, Shafie $A A$, Hassali MAA. Evaluation of potentially inappropriate medications among older residents of Malaysian nursing homes. Int J Clin Pharm 2012; 34(4): 596-603.

38. Lee SJ, Cho SW, Lee YJ, Choi JH, Ga H, Kim YH, Woo SY, Jung WS, Han DY. Survey of potentially inappropriate prescription using STOPP/START criteria in Inha University Hospital. Korean J Fam Med 2013; 34(5): 319-326.

39. Barry PJ, Gallagher P, Ryan C, O'mahony D. START (screening tool to alert doctors to the right treatment)-an evidence-based screening tool to detect prescribing omissions in elderly patients. Age Ageing 2007; 36(6): 632-638.

40. Hill-Taylor B, Sketris I, Hayden J, Byrne S, O'Sullivan D, Christie R. Application of the STOPP/START criteria: A systematic review of the prevalence of potentially inappropriate prescribing in older adults, and evidence of clinical, humanistic and economic impact. J Clin Pharm Ther 2013; 38(5): 360-372. 